\title{
Ovarian cystadenofibroma mimicking malignancy: role of frozen section - a case report
}

\author{
Sarvottma Antil* \\ Department of Obstetrics \& Gynaecology, Kalpana Chawla Govt. Medical College, Karnal, Haryana, India \\ Received: 07 November 2015 \\ Revised: 16 November 2015 \\ Accepted: 15 December 2015 \\ *Correspondence: \\ Dr. Sarvottma Antil, \\ E-mail: sarvottma_antil@yahoo.com \\ Copyright: ( ) the author(s), publisher and licensee Medip Academy. This is an open-access article distributed under \\ the terms of the Creative Commons Attribution Non-Commercial License, which permits unrestricted non-commercial \\ use, distribution, and reproduction in any medium, provided the original work is properly cited.
}

\begin{abstract}
Ovarian cystadenofibroma is a rare benign neoplasia whose radiological and macroscopic appearance mimicks malignancy. This case report highlights the importance of intraoperative frozen section in avoiding an inappropriate extensive surgery for this benign disease. A case study of 28 year old unmarried female with a complex unilateral ovarian cyst, with radiological features suggestive of malignancy. Laparoscopic cystectomy was carried out and an intraoperative frozen section of the tissue was ordered. Frozen section examination pointed towards the benign nature of the tumor and hence inappropriate extensive surgery was avoided. A benign tumor like ovarian cystadenofibroma, which otherwise mimicks malignancy, can be proven to be benign by an intraoperative frozen section examination. Hence an unnecessary aggressive surgical management can be avoided.
\end{abstract}

Keywords: Ovarian cystadenofibroma, Benign neoplasia, Malignancy, Frozen section

\section{INTRODUCTION}

Ovarian cystadenofibroma is a composite neoplasia that has neoplastic glandular elements with stroma, with large cystic spaces present within the glandular elements. Though believed to be rare, some investigators are of opinion that it is more common than the reported cases. It is rarely malignant, but it often mimics malignancy on imaging and macroscopic examination. However, a frozen section examination can prove this neoplasia to be benign, therefore, unnecessary aggressive surgical management can be avoided, as in the following case report.

\section{METHODS}

\section{Case history and examination}

A 28 year old unmarried lady with no physical complaints, presented with an abnormal routine pelvic ultrasound with findings suggestive of a pelvic mass. She had no history of abdominal discomfort, nausea, bloating. There was no history of anorexia or weight loss. She had no menstrual irregularities. Last menstrual period was two weeks prior to the date of presentation. There was no history of any ovarian neoplasia in mother/siblings.

On general physical examination no significant findings were present. On per abdomen examination, no palpable mass was observed and there was no evidence of ascites or organomegaly. A per speculum and per vaginum examination was not done as it was not consented upon by the patient.

\section{Investigations}

Transabdominal sonographic findings (Figure 1) - A well-defined cystic lesion of size $6.4 \times 4.6 \mathrm{~cm}$ are seen involving the left adnexal region, abutting the left ovary. Multiple well defined mural nodules are seen on anterior and posterior wall of the lesion, largest one measuring 2.3 $\mathrm{X} 1 \mathrm{~cm}$. Right ovary is normal. 
CA-125 levels were investigated and were found out to be $35.40 \mathrm{U} / \mathrm{ml}$. In view of complex nature of the adnexal mass and borderline CA - 125 levels, an MRI was carried out, findings of which are described below.

Figure 2 is a T2 weighted coronal MR image with fat suppression showing a hypointense rounded solid cystic lesion in left adnexa, measuring $5.3 \times 6.2 \times 6.3 \mathrm{~cm}$, displacing the uterus laterally. Lesion has hypointense internal septa measuring $4.9 \mathrm{~mm}$ in width. Lesion shows multiple nodular solid peripheral intraluminal projecting excrescences, average size 5-6 mm.

Figure 3 is a T1 weighted coronal post Gadolinium contrast MR image, with the nodular solid peripheral excrescences showing homogenous enhancement, without any enhancement of cystic component.

All routine pre-operative investigations were within normal limits.

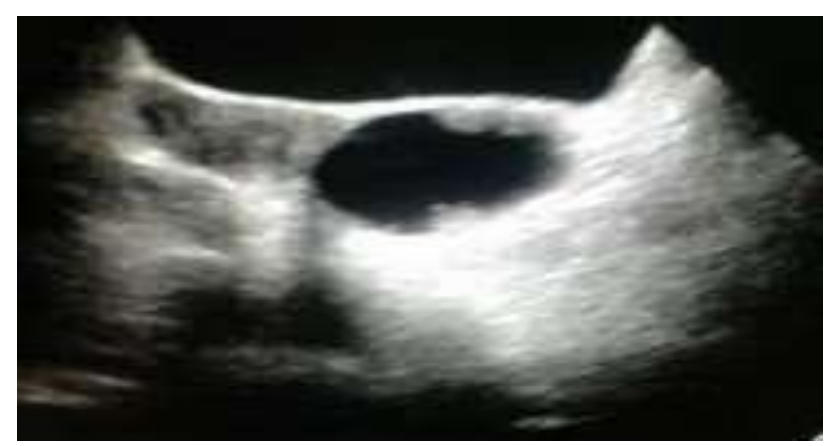

Figure 1: Transabdominal sonographic findings of a well-defined cystic lesion (size $6.4 \times 4.6 \mathrm{~cm}$ ) is seen involving the left adnexal region, abutting the left ovary. Multiple well defined mural nodules are seen on anterior and posterior wall of the lesion (largest one measuring $2.3 \mathrm{X} 1 \mathrm{~cm})$.

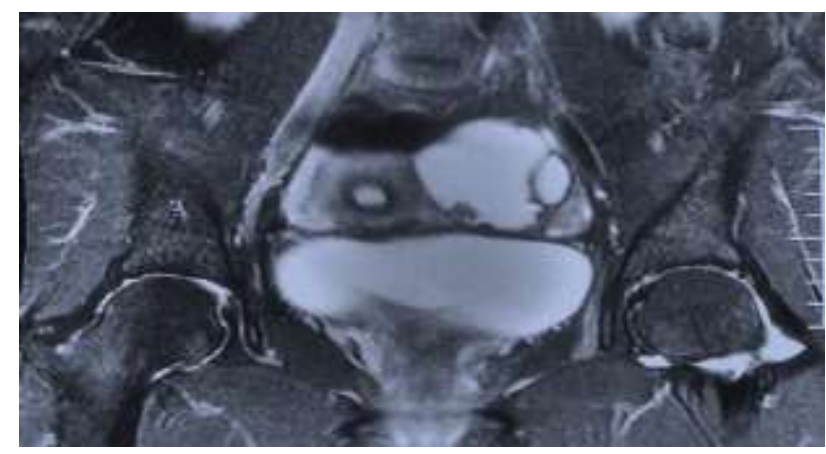

Figure 2: T2 weighted coronal MR image with fat suppression showing a hypointense rounded solid cystic lesion in left adnexa (measuring $5.3 \times 6.2$ X 6.3 $\mathrm{cm}$ ), displacing the uterus laterally. Lesion has hypointense internal septa (measuring $4.9 \mathrm{~mm}$ in width). Lesion shows multiple nodular solid peripheral intraluminal projecting excrescences (average size $5-6 \mathrm{~mm}$ ).

\section{Management}

Decision for laparoscopic cystectomy was taken, with prior consents for laparotomy and left salpingooophorectomy, if needed. Intraoperatively, the upper abdomen was normal. A left ovarian cyst with smooth outer surface was seen. There was no evidence of ascites or lymphadenopathy. Peritoneal fluid was sent for cytology. Laparoscopic cystectomy was done. On gross examination the outer surface of the cyst was smooth. Cyst was filled with clear fluid. On cut section, the inner surface of cyst showed presence of papillary excrescences. Frozen section was sent to decide further course of action. The frozen section reported the tissue as a likely cystadenofibroma, negative for malignancy.

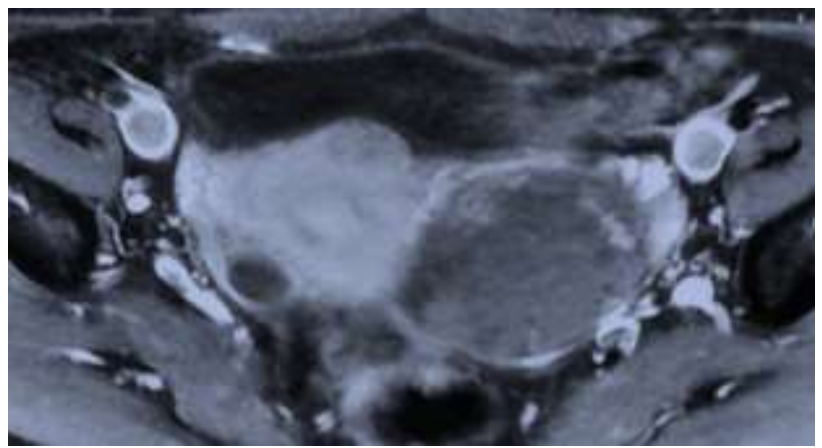

Figure 3: T1 weighted coronal post Gadolinium contrast MR image, with the nodular solid peripheral excrescences showing homogenous enhancement, without any enhancement of cystic component.

Surgery was concluded after laparoscopic cystectomy. Frozen section report was confirmed by detailed histopathological examination. Detailed histopathological examination reported the tissue to be a benign papillary serous cystadenofibroma, negative for malignancy. Peritoneal cytology was reported as negative for malignant cells.

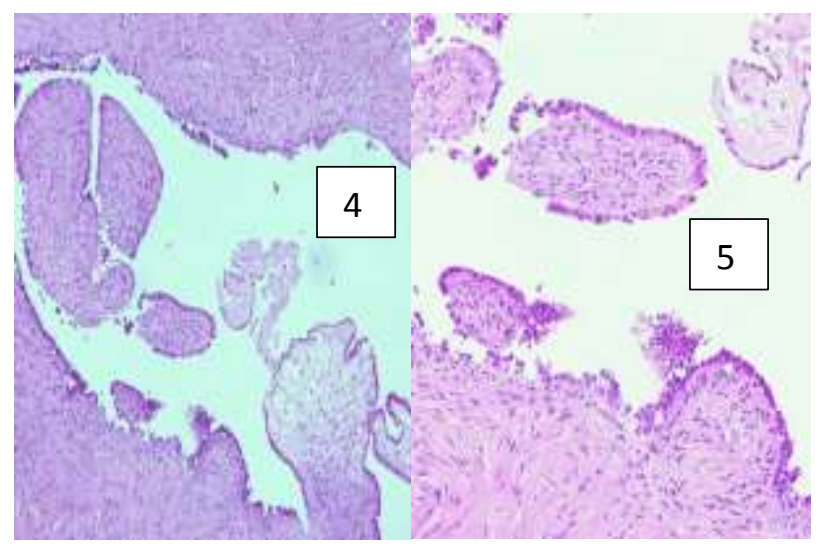

Figure 4 \& 5: Photomicrographs showing low columnar epithelium lining the papillae with a fibrous stroma. 
Figure 4, 5 are photomicrographs showing low columnar epithelium lining the papillae with a fibrous stroma.

Ovarian cystadenofibromas can mimic features of malignancy on radiological and macroscopic examination. Intraoperative frozen section examination can assess the benign nature of tumor. Therefore, an inappropriate extensive surgery can be avoided.

\section{DISCUSSION}

Ovarian cystadenofibroma is a relatively rare neoplasia, seen in women of $15-65$ year age group. ${ }^{1,2}$ It comprises of epithelial and fibrous stromal components. It is rarely malignant, but it often mimics malignancy on imaging due to the solid component and/or thick septae. Gross examination of these tumors during surgery may be deceptive, with these masses resembling malignant tumors. Intraoperative frozen section examination can assess the benign nature of a tumor which on preoperative imaging and morphological examination, closely mimics malignancy. Therefore, an inappropriate extensive surgery can be avoided, as highlighted by this case report.

Funding: No funding sources

Conflict of interest: None declared

Ethical approval: Not required

\section{REFERENCES}

1. Cho SM, Byun JY, Rha SE, Jung SE, Park GS, Kim $\mathrm{BK}$, et al. CT and MRI findings of cystadenofibromas of the ovary. Eur Radiol. 2004;14:798-804.

2. Czernobilsky B, Borenstein R, Lancet $\mathrm{M}$. Cystadenofibroma of the ovary. A clinicopathologic study of 34 cases and comparison with serous cystadenoma. Cancer. 1974;34:1971-81.

Cite this article as: Antil S. Ovarian cystadenofibroma mimicking malignancy: role of frozen section - a case report. Int J Reprod Contracept Obstet Gynecol 2016;5:249-51. 